\title{
Development of Loop-Mediated Isothermal Amplification Assays for the Detection of Seedborne Fungal Pathogens Fusarium fujikuroi and Magnaporthe oryzae in Rice Seed
}

Sara Franco Ortega, Centre of Competence for the Innovation in the Agro-Environmental Sector-Agroinnova, and Department of Agricultural, Forestry and Food Sciences (DiSAFA), University of Turin, I-10095 Grugliasco, TO, Italy; Jenny Tomlinson and Jennifer Hodgetts, FERA, Sand Hutton, York, United Kingdom; Davide Spadaro ${ }^{\dagger}$ and Maria Lodovica Gullino, Centre of Competence for the Innovation in the Agro-environmental Sector-Agroinnova, and DiSAFA, University of Turin; and Neil Boonham, FERA, and IAFRI, Newcastle University, Newcastle upon Tyne NE1 7RU, United Kingdom

\begin{abstract}
Bakanae disease (caused by Fusarium fujikuroi) and rice blast (caused by Magnaporthe oryzae) are two of the most important seedborne pathogens of rice. The detection of both pathogens in rice seed is necessary to maintain high quality standards and avoid production losses. Currently, blotter tests are used followed by morphological identification of the developing pathogens to provide an incidence of infection in seed lots. Two loop-mediated isothermal amplification assays were developed with primers designed to target the elongation factor 1- $\alpha$ sequence of $F$. fujikuroi and the calmodulin sequence of M. oryzae. The specificity, sensitivity, selectivity, repeatability, and

reproducibility for each assay was assessed in line with the international validation standard published by the European and Mediterranean Plant Protection Organization (PM7/98). The results showed a limit of detection of 100 to $999 \mathrm{fg}$ of DNA of F. fujikuroi and 10 to $99 \mathrm{pg}$ of M. oryzae DNA. When combined with a commercial DNA extraction kit, the assays were demonstrated to be effective for use in detection of the pathogens in commercial batches of infected rice seed of different cultivars, giving results equivalent to the blotter method, thus demonstrating the reliability of the method for the surveillance of $F$. fujikuroi and M. oryzae in seed-testing laboratories.
\end{abstract}

Cereals represent $40 \%$ of the global crop yield (tons) (Oerke and Dehne 2004), and rice is second only to wheat in the amount produced. Rice feeds over half the world's population and supplies $70 \%$ of their daily calories, especially in Asia (Delseny et al. 2001), where it is a staple crop for over 3 billion people.

The number of organisms that threaten rice production is extremely high and, therefore, the maintenance of high-quality rice seed is necessary to secure food availability and reach high quality standards (Teng 1994). Until now, the treatments against seedborne pathogens have been carried out using fungicides that allow pathogens to be eradicated or reduced, especially on commercial seed where healthy certified seed, free from pathogens, are required.

Seedborne plant pathogens can cause important yield and quality losses as well as being an unnoticed source of pathogen spread and dissemination (Du Toit 2004).

Magnaporthe oryzae B. C. Couch (anamorph: Pyricularia oryzae Cavara) is a hemibiotrophic pathogen and the causal agent of rice blast and leaf spot in over 50 grass species (Ou 1985). Rice blast is the most destructive rice disease, and it is endemic in all ricegrowing areas (Manandhar et al. 1998). The high adaptability of rice to different weather conditions makes it ideal for cultivation in different parts of the world, including Asia, Africa, and America as well as Mediterranean countries such as Italy, Spain, and Portugal. European countries are characterized by unfavorable weather conditions for the development of blast disease in the dry season but, at the end of the

${ }^{\dagger}$ Corresponding author: D. Spadaro; E-mail: davide.spadaro@unito.it

Funding: The research leading to these results has received funding from the European Union's Horizon 2020 Framework Programme under grant agreement number 634179 - EMPHASIS (Effective Management of Pests and Harmful Alien Species-Integrated Solutions).

*The $\boldsymbol{e}$-Xtra logo stands for "electronic extra" and indicates that four supplementary tables are published online.

Accepted for publication 16 February 2018.

C 2018 The American Phytopathological Society season, long periods of wet weather can favor panicle infection, blast development, and related yield losses (Chataigner 1996). M. oryzae is widespread in rice seed, as indicated by recent analyses performed on seed of different rice varieties.

Fusarium fujikuroi Nirenberg (teleomorph Gibberella fujikuroi (Sawada) S. Ito) is both a seed- and soilborne pathogen, and it is the causal agent of bakanae disease. F. fujikuroi was initially described as Lisea fujikuroi Sawada, in 1919, and later renamed G. fujikuroi by Sun and Snyder (1981).F. fujikuroi is part of the G. fujikuroi species complex (GFSC), which is formed by monophyletic lineages with anamorphs in Fusarium spp. (O'Donnell and Cigelnik 1997). Many of the species within this complex are pathogenic and important producers of secondary metabolites, including phytohormones and mycotoxins (Siciliano et al. 2015). Bakanae has become more widespread over the years, threatening rice-producing countries such as Japan, Korea, Thailand, Taiwan, India, the Philippines, Italy, Portugal, Spain, and the United States (Bashyal et al. 2014). Under favorable conditions for the disease, bakanae can cause yield losses up to 10 to $20 \%$. Severe infections, due to secondary infection through conidia dissemination, can reach $70 \%$ of rice plants (Ito and Kimura 1931; Ou 1985). Chemical seed dressing has been the most common way of controlling fungal diseases in rice; however, with the reduction in fungicide usage in the European Union, the incidence of some rice diseases has increased and it can now be difficult to source pathogenfree certified seed (Matic et al. 2017).

In order to achieve faster pathogen identification, nucleic acidbased methods have become widespread. Typically, molecular methods have high specificity and sensitivity and are much quicker to perform than morphological identification using microscopy (Boonham et al. 2008). Specific primers and probes for end-point and real-time polymerase chain reaction (PCR) (TaqMan) assays have been developed by Amatulli et al. (2012) and Amaral Carneiro et al. (2017), designed to target the elongation factor $1-\alpha(\mathrm{EF}-1 \alpha)$ region to detect F. fujikuroi. while a real-time PCR (TaqMan) assay for M. oryzae, designed to amplify a unigene scytolone dehydratese, has been developed by Su'udi et al. (2013).

Loop-mediated isothermal amplification (LAMP) is a DNA amplification method that can be used to amplify nucleic acid in a targetspecific way without the need for thermal cycling (Nagamine et al. 2001; Notomi et al. 2000). LAMP uses enzymes that are less affected 
by compounds that inhibit PCR and, as a result, can be easier and quicker to perform than PCR-based methods because complex DNA extraction is not required. The enzymes tend to copy faster than PCR and the lack of thermal cycling means that reactions can be run on hand-held, battery-powered platforms such at the Genie III (OptiGene Ltd.). Taken together, these characteristics identify LAMP as being well suited to diagnostic use and also facilitates the potential use of LAMP in remote locations such as seed stores, pack houses, or directly in the field as an alternative to sending samples to a centralized testing laboratory. The LAMP method has been demonstrated for the detection of bacteria (Hodgetts et al. 2015), fungi (Tomlinson et al. 2010a), phytoplasma (Hodgetts et al. 2011), and viruses (Tomlinson et al. 2013). The LAMP product can be visualized by means of gel electrophoresis, magnesium pyrophosphate precipitation, turbidimetric reactions (Mori et al. 2004), and colorimetric reactions using color-changing reagents such as hydroxy naphthol blue (Goto et al. 2009). However, due the large amount of target DNA amplified during a LAMP reaction, closed-tube methods for resolving results are preferable and real-time methods based on turbidity (Mori et al. 2004) or fluorescence (Tomlinson et al. 2010b,c) are better suited for routine diagnostics.

The efficient detection of $F$. fujikuroi and $M$. oryzae is essential during seed certification and to allow early containment and control measures to be implemented. Two LAMP assays have been developed in this study for the detection of F. fujikuroi and M. oryzae on rice. We have explored the use of the assays for more rapid seed testing and have validated the tests to the international validation standard published by the European and Mediterranean Plant Protection Organization (EPPO) (PM7/98).

\section{Materials and Methods}

Fungal isolates. All samples used for DNA extraction are listed in Table 1. The isolates, belonging to the genus Magnaporthe, were kindly provided by Dr. Didier Tharreau (Unité Mixte de Recherche, Biologie et Génétique des Interactions Plante-Parasite, Montpellier, Franc). The GFSC isolates and the fungi commonly found in rice paddies used in this study were obtained from Agroinnova (University of Turin, Italy) and FERA (York, United Kingdom). Fusarium isolates had previously been identified by sequencing using EF- $1 \alpha$ analysis, using EF1/EF2 primers that provide species-level discrimination (Geiser et al. 2004). The fungal isolates were stored at $-80^{\circ} \mathrm{C}$ in $20 \%$ glycerol.

DNA extraction from the fungal cultures. Each single-spore culture of the isolates listed in Table 1 was grown in potato dextrose broth (PDB; Sigma-Aldrich) on a rotary shaker (120 rpm) for 10 days at room temperature. Mycelium was collected by means of filtration through Whatman number 1 filter paper and then stored at $-20^{\circ} \mathrm{C}$. The total genomic DNA was obtained using an E.Z.N.A Fungal DNA mini kit (OMEGA Bio-Tek), according to the manufacturer's instructions. The DNA concentration of each isolate was measured by Nanodrop 2000 (Thermo Fisher) and was adjusted to 1 to $50 \mathrm{ng} / \mu \mathrm{l}$.

LAMP reactions. Six LAMP primers-external primers F3 and B3, internal primers (FIP and BIP), and loop primers (F-loop and B-loop-were designed for both targets, according to the methods reported by Notomi et al. (2000).

The calmodulin sequence was used to design specific LAMP primers for M. oryzae. Sequence alignment using MEGA 6.0.6 was carried out using the sequence of several isolates of $M$. oryzae and its closest species, M. grisea (Choi et al. 2013), as well as other Pyricularia spp. (GenBank accession numbers AF396017, AF396019, AF396013, AF396027, AF396022, AF396020, AF306910, AF396011, AY063738, KC167645, AY063739, KC167646, AF396012, KC167624, KC167601, AF396008, AF396005, KC167639, and KC167643).

The LAMP primers for $F$. fujikuroi were designed on the basis of the EF-1 $\alpha$ sequence. This gene was characterized by a 6-bp deletion in the sequence of all of the strains of $F$. fujikuroi in the 688 position in the second intron of the EF- $1 \alpha$ gene, as reported by Amatulli et al. (2012). The sequence alignment carried out using MEGA 6.0.6. included the following strains of the GFSC: F. commune, $F$. andiyazi, $F$. graminearum, $F$. proliferatum, $F$. verticillioides, $F$. oxysporum, and
F. equiseti, as well as some $F$. fujikuroi isolates (GenBank accession numbers KR071742, KR071743, KR071745, KR071744, AF160279, KR071746, JN092344, HM804942, KC954401, JX118988, KR071740, KR071703, KT794174, and KF499577).

The possibility of secondary structures and hairpins was checked by using OligoCalc (http://biotools.nubic.northwestern.edu/OligoCalc. html). A BLASTn analysis of the target sequence was carried out to evaluate the specificity of the primers. The primers were synthesized and high-performance liquid chromatography purified by Eurofins and can be obtained with positive controls material as a kit from OptiGene Ltd.

The LAMP reactions were carried out with $1 \mu$ l of DNA of the different isolates, with the concentration adjusted to 1 to $30 \mathrm{ng} / \mu \mathrm{l}$ or $1 \mu l$ of the crude extractions. The $25-\mu l$ reaction included the external primers (F3 and B3) at $0.2 \mu \mathrm{mol} /$ liter, each internal primer (FIP and BIP) at $2 \mu \mathrm{mol} / \mathrm{liter}$, each loop primer at $1 \mu \mathrm{mol} / \mathrm{liter}$, and $1 \times$ Isothermal Mastermix ISO-004 (OptiGene Ltd.). Amplification was performed for $45 \mathrm{~min}$ at $65^{\circ} \mathrm{C}$, after which the annealing temperature was measured by recording fluorescence while cooling from 95 to $70^{\circ} \mathrm{C}$ at $0.05^{\circ} \mathrm{C} / \mathrm{s}$ using a Genie_ II instrument (OptiGene Ltd.). Negative controls with water were included in each run. The same amplification protocol was adopted on a StepOne instrument (Applied Biosystems) to test the rice. The Real-Time machine was set up using a quantification experiment type with standard curve with TaqMan reagents (FAM as reporter and NFQ-MGB as quencher). The program was set up to do 40 cycles at $65^{\circ} \mathrm{C}$ with fluorescence measured each minute and a melting curve with the following steps: $95^{\circ} \mathrm{C}$ for $15 \mathrm{~s}, 70^{\circ} \mathrm{C}$ for $1 \mathrm{~min}$, and an increase of the temperature to $95^{\circ} \mathrm{C}$ at $0.3^{\circ} \mathrm{C} / \mathrm{s}$ to record the fluorescence At the same time, a cytochrome oxidase gene LAMP assay, developed by Tomlinson et al. (2010b), was used as internal control to detect the plant DNA and to confirm the DNA presence in case of negative results in the LAMP assays made just after crude extraction.

Rice seed batches. Pathogen-free seed of rice cultivar Dorella confirmed by potato dextrose agar (PDA) test (Mathur and Kongsdal 2003) were artificially infected to check the lowest infection rate which could be detected using the LAMP assays. In order to verify the absence of natural infection from the two target pathogens, 400 seeds were placed onto PDA (Sigma-Aldrich) (25 seeds/Petri dish) and left for 7 days at $22^{\circ} \mathrm{C}$ in alternating 12-h light-darkness cycles. After this check, rice seed were treated with sodium hypochlorite (2\%) for $2 \mathrm{~min}$, rinsed with distilled water, then air dried for 30 min. Single-spore cultures of $F$. fujikuroi $\mathrm{CsC} 8$ and M. oryzae Guy11 grown on PDB (Sigma Aldrich) for 7 days at room temperature were filtered through sterilized cotton cheesecloth and brought to a concentration of $2 \times 10^{5} \mathrm{CFU} / \mathrm{ml}$ for $\mathrm{CsC} 8$ and $3.3 \times 10^{3} \mathrm{CFU} / \mathrm{ml}$ for $M$. oryzae Guy11, by counting with a hemocytometer. Both concentrations were 10 -fold serial diluted to $20 \mathrm{CFU} / \mathrm{ml}$ for $F$. fujikuroi $\mathrm{CsC} 8$ and $33 \mathrm{CFU} / \mathrm{ml}$ for $M$. oryzae Guy 11 . In all, 300 rice seeds were inoculated with 7-day-old conidial suspensions, incubated on a rotary shaker at $90 \mathrm{rpm}$ for $45 \mathrm{~min}$, and air dried overnight. The effective concentration in number of conidia on the rice seed was determined using real-time PCR (TaqMan) (Supplementary Tables S2 and S3). Infected rice seed batches were prepared at 4.0, 6.6, 8.0, 13.3, and $33.3 \%$ by mixing infected seed with healthy seed at different ratios: 1 infected seed in 24 healthy seeds for $4.0 \%$ infected rate, 1 infected seed in 14 healthy seeds for $6.6 \%$ infected rate, 2 infected seeds in 23 healthy seeds for $8 \%$ infected rate, 2 infected seeds in 13 healthy seeds for $13.3 \%$ infected rate, and 5 infected seeds in 10 healthy seeds for $33.3 \%$ infected rate. Four seed batches representing biological replicates were prepared: three replicates for crude DNA extraction method (explained below) and one for the E.Z.N.A Plant DNA kit extraction (OMEGA Bio-Tek).

Rice seed DNA extraction. Alkaline DNA extraction (Chomczynski and Rymaszewski 2006), used as crude extraction method, was modified for rice seed batches. One 7/16-in. stainless steel 316 GD ball (Spheric Trafalgar Ltd.) and $2 \mathrm{ml}$ of $\mathrm{pH} 13$ polyethylene glycol (PEG) buffer (PEG at $50 \mathrm{~g} \mathrm{liter}^{-1}$, average Mn 4,600, and $\mathrm{KOH}$ at $20 \mathrm{mmol} /$ liter; $\mathrm{pH}$ 13.5) were placed in a 5-ml tube and homogenized by vigorous manual shaking for $3 \mathrm{~min}$. Three individual rice seeds at 
Table 1. Isolates used in this study

\begin{tabular}{|c|c|c|c|}
\hline Isolate code & Species & Geographical origin & Year of isolation \\
\hline 11.3 & Fusarium fujikuroi & Italy & 2006 \\
\hline VPG2 & F. fujikuroi & Italy & 2008 \\
\hline G3S & F. fujikuroi & Italy & 2008 \\
\hline VPG4 & F. fujikuroi & Italy & 2008 \\
\hline CsSP1 & F. fujikuroi & Italy & 2009 \\
\hline CsAg3 & F. fujikuroi & Italy & 2009 \\
\hline CS.C8 & F. fujikuroi & Italy & 2009 \\
\hline $\mathrm{GCe} 2$ & F. fujikuroi & Italy & 2009 \\
\hline M1149 & F. fujikuroi & Taiwan & Unknown \\
\hline $19-113$ & F. proliferatum & Italy & 2006 \\
\hline $11-47$ & F. proliferatum & Italy & 2006 \\
\hline FP1 & F. proliferatum & Italy & Unknown \\
\hline FP2 & F. proliferatum & Italy & Unknown \\
\hline FP3 & F. proliferatum & Italy & Unknown \\
\hline 1100 & F. proliferatum & Unknown & Unknown \\
\hline $2-130$ & F. napiforme & Italy & 2006 \\
\hline FA1 & $F$. andiyazi & Italy & Unknown \\
\hline FA2 & F. andiyazi & Italy & Unknown \\
\hline $\mathrm{FC} 1$ & F. commune & Italy & Unknown \\
\hline $\mathrm{FC} 2$ & F. commune & Italy & Unknown \\
\hline $\mathrm{FC} 3$ & F. commune & Italy & Unknown \\
\hline $19-9$ & F. verticillioides & Italy & 2006 \\
\hline FV3 & F. verticillioides & Italy & Unknown \\
\hline FV2 & F. verticillioides & Italy & Unknown \\
\hline Mya3040 & F. oxysporum f. sp. lactucae & Italy & 2002 \\
\hline Gr15 & F. oxysporum f. sp. raphani & Italy & Unknown \\
\hline ATCC52557 & F. oxysporum f. sp. conglutinans & Unknown & Unknown \\
\hline ATCC58385 & F. oxysporum f. sp. conglutinans & Unknown & Unknown \\
\hline ATCC52422 & F. oxysporum f. sp. chrysantemi & Unknown & Unknown \\
\hline ATCC744009 & F. oxysporum f. sp. fragariae & Unknown & Unknown \\
\hline HPV04 & F. graminearum & Unknown & Unknown \\
\hline 1498 & $F$. graminearum & Unknown & Unknown \\
\hline 822 & F. sporotrichioides & Unknown & Unknown \\
\hline 575 & F. sulphureum & Unknown & 1991 \\
\hline 710 & F. poae & United Kingdom & 1993 \\
\hline L8FEQ & F. equiseti & Unknown & Unknown \\
\hline 832 & F. culmorum & Unknown & Unknown \\
\hline 1098 & F. trienetrum & Unknown & Unknown \\
\hline 54 & F. avenaceae & Unknown & 1991 \\
\hline FP & F. panidoroserum & Unknown & Unknown \\
\hline RS1 & Rhizoctonia solani & Unknown & Unknown \\
\hline E.S. 34015 & Alternaria alternata & Unknown & Unknown \\
\hline Py5.10 & Pythium ultimum & Unknown & Unknown \\
\hline Scscletìro1 & Sclerotinia sclerotiorum & Unknown & Unknown \\
\hline Scmin 1 & S. minor & Unknown & Unknown \\
\hline Vertsp1 & Verticillium & Unknown & Unknown \\
\hline $\mathrm{CV} 1$ & Curvularia sp. & Unknown & Unknown \\
\hline 1095 & Cochliobolus & Unknown & 2000 \\
\hline 1238 & Cochliobolus & Unknown & 1998 \\
\hline PE1 & Phoma exigua & Unknown & Unknown \\
\hline $\mathrm{TC} 1$ & Trichoderma & Unknown & Unknown \\
\hline $\mathrm{CO} 1$ & Colletotrichum sp. & Unknown & Unknown \\
\hline $\mathrm{PF} 1$ & Penicillium expansum & Unknown & Unknown \\
\hline br0011-Guy11 & Magnaporthe oryzae & South America & 1978 \\
\hline br0156 & M. oryzae & Africa & 1989 \\
\hline br0071-GrF2 & M. oryzae & United States & 1998 \\
\hline MO1 & M. oryzae & Unknown & Unknown \\
\hline AG0041 & M. oryzae & Unknown & Unknown \\
\hline AG0043 & M. oryzae & Unknown & Unknown \\
\hline br0029 & M. grisea & Brazil & 1989 \\
\hline br0067 & Pyricularia pennisetigena & Brazil & 1990 \\
\hline br0017 & P. penniseticola & Africa & 1990 \\
\hline br0001-RG1 & P. zingibericola & Indian Ocean & Unknown \\
\hline br0001-CT4 & P. ctenantheicola & Greece & 1998 \\
\hline $\mathrm{BO} 3$ & Bipolaris oryzae & Unknown & Unknown \\
\hline BO5 & B. oryzae & Unknown & Unknown \\
\hline
\end{tabular}


different inoculum concentrations and one seed batch for each inoculum concentration and infection ratio were ground with liquid nitrogen. All of the plant material was extracted with the E.Z.N.A Plant DNA kit (OMEGA Bio-Tek) according to the manufacturer's instructions, to compare the reliability of the crude extraction method and to check whether the LAMP reaction would be affected by inhibitors.

Real-time PCR. Ten-fold diluted DNA $(1 \mu \mathrm{l})$ from each DNA extraction method was used to measure the target concentrations by quantitative real-time PCR (qPCR) on an ABI Prism 7900HT instrument (Applied Biosystems) and to conduct a comparative analysis with the LAMP assay for both $M$. oryzae and $F$. fujikuroi. To quantify $M$. oryzae, a real-time PCR designed on the MHP1 gene was carried out in triplicate under the following conditions, described by Su'udi et al. (2013): an initial denaturation at $95^{\circ} \mathrm{C}$ for $4.5 \mathrm{~min}$, followed by 40 cycles of $15 \mathrm{~s}$ at $95^{\circ} \mathrm{C}$ and $15 \mathrm{~s}$ at $60^{\circ} \mathrm{C}$. A standard curve was obtained using 10-fold dilutions of the previously measured DNA samples of $M$. oryzae, ranging from DNA at $1.37 \mathrm{ng} / \mu \mathrm{l}$ to $0.137 \mathrm{fg} / \mu 1$, tested in triplicate. The real-time PCR primers and probe designed by Amaral Carneiro et al. (2017) were used to quantify $F$. fujikuroi in the rice seed. The reaction was carried out in triplicate, with an initial incubation at $50^{\circ} \mathrm{C}$ for $2 \mathrm{~min}, 95^{\circ} \mathrm{C}$ for $10 \mathrm{~min}$, and 40 cycles at $95^{\circ} \mathrm{C}$ for $15 \mathrm{~s}$ and at $62^{\circ} \mathrm{C}$ for $1 \mathrm{~min}$. A standard curve was obtained by making serial dilutions of $F$. fujikuroi DNA ranging from $6.18 \mathrm{ng} / \mu \mathrm{l}$ to $0.618 \mathrm{fg} / \mu \mathrm{l}$. Positive (fungal DNA) and negative (water) controls were included in both experiments. The average of the three technical replicates of the real-time PCR assay was used to calculate the DNA quantity of each individual seed and seed batch. The number of detected cells was then calculated by dividing the DNA quantity by the weight of the genome of each pathogen: $0.00004756 \mathrm{ng}$ for $F$. fujikuroi (Jeong et al. 2013) and $0.0000378 \mathrm{ng}$ for M. oryzae (Kumar et al. 2017). The cycle threshold (Ct) values generated by the real-time assay were compared with the standard curve to obtain the amount (in nanograms) of each positive result.

Validation of the LAMP assays. Both tests were validated according to the EPPO PM7/98 standard, by evaluating the selectivity, specificity, sensitivity, repeatability, and reproducibility. The specificity panel was composed of $9 F$. fujikuroi isolates, 30 isolates of phylogenetically closely related Fusarium spp., 6 M. oryzae isolates, and 5 isolates of phylogenetically closely related Magnaporthe spp., together with other rice pathogens. All of the samples were used in three independent assays for each test. The sensitivity was checked by using 10-fold serial dilutions of DNA extracted from pure culture of two different isolates of $M$. oryzae and from four isolates of $F$. fuji$k u r o i$, and DNA from seed. The seed testing included individual rice seeds inoculated at different concentrations (from $2 \times 10^{5}$ cells $/ \mathrm{ml}$ to 20 cells $/ \mathrm{ml}$ for $F$. fujikuroi $\mathrm{CsC} 8$ isolate, and from $3.3 \times 10^{3}$ cells $/ \mathrm{ml}$ to 33 cells $/ \mathrm{ml}$ for $M$. oryzae Guy11) and seed batches with different infection ratios, as previously described. The selectivity of the LAMP assays was evaluated using seed from different rice cultivars (Carnise, Deneb, Selenio, Galileo, and Dorella) naturally infected with $M$. ory$z a e$ or F. fujikuroi. Different artificially inoculated seed batches were used to determine the infection rate, which was established by using the LAMP assay, and to evaluate the in vivo sensitivity.

For repeatability and reproducibility, the DNA was extracted with both methods. Five individual seeds (biological replicates), inoculated at different concentrations $\left(2 \times 10^{5}\right.$ and $2 \times 10^{4} \mathrm{CFU} / \mathrm{ml}$ for $\mathrm{CsC} 8$ and $3.3 \times 10^{3} \mathrm{CFU} / \mathrm{ml}$ for $M$. oryzae Guy 11 ), were extracted with the crude extraction method, while three seeds were extracted with the kit extraction method. Regarding the four seed batches, three of them were extracted with the crude extraction method, while the fourth was extracted with the kit extraction method. Individual seeds and seed batches were quantified in triplicate (technical replicates) with the real-time PCR and the LAMP assay. Repeatability was checked by running three independent assays for each pathogen (taking into account the results of the biological and technical replicates), while reproducibility was tested by different operators on different days with different machines.

Identity of LAMP products for $\boldsymbol{F}$. fujikuroi. For the $F$. fujikuroi assay, to confirm the identity of the crude extracted samples, which gave an annealing temperature lower than the pure DNA, the LAMP products $(1 \mu \mathrm{l})$ were digested with either $M s p \mathrm{I}$ or $P v u \mathrm{I}$, according to the manufacturer's instructions (Promega Corp.). The reaction mixtures were incubated at $37^{\circ} \mathrm{C}$ for $1 \mathrm{~h}$ and the digestion products were visualized in $3 \%$ agarose gels. The profiles were compared with a GeneRuler 100-bp DNA ladder (Thermo Scientific).

To explore the impact of crude extraction on the recorded annealing temperature, an $F$. fujikuroi CsC8 LAMP product, with an annealing temperature of $88.2^{\circ} \mathrm{C}$, was used. The LAMP product was twofold serially diluted, and $1 \mu l$ of each dilution was combined with $24 \mu \mathrm{l}$ of Mastermix ISO-004 and primers, at the same conditions described above to replicate the LAMP assay. At the same time, the DNA of each dilution $(1 \mu \mathrm{l})$ was combined with $23 \mu \mathrm{l}$ of Mastermix ISO-004 and primers and $1 \mu$ l of the crude seed extract. The annealing temperature of both experiments was obtained with a Genie II instrument.

Field samples. Rice seed from the five rice cultivars described above were used to check the reliability of the LAMP assay. The DNA of 400 rice seeds, divided into 25 -seed subsamples per cultivar, were extracted using the crude extraction method and the E.Z.N.A Plant DNA kit (OMEGA Bio-Tek). LAMP assays were carried out as described above with a StepOne Plus Real-Time PCR system (Applied Biosystems), using $1 \mu \mathrm{l}$ of the extraction and recording the $\mathrm{Ct}$ values as the time to positive (Tp), a parameter analogous to the threshold cycling time in PCR (Tomlinson et al. 2013).

The same rice cultivar samples were plated on PDA to check for the presence of $F$. fujikuroi and $M$. oryzae, as described by Mathur and Kongsdal (2003), and were morphologically identified after 7 days at room temperature and alternating 12-h light-darkness cycles.

Genomic DNA was extracted from some single-spore colonies of the Fusarium spp. isolated from rice seed as described above to determine the species using DNA barcoding as follows. The EF- $1 \alpha$ gene was amplified using the EF1 and EF2 primers under the following conditions: $94^{\circ} \mathrm{C}$ for $5 \mathrm{~min}$; followed by 40 cycles of $94^{\circ} \mathrm{C}$ for 45 $\mathrm{s}, 58^{\circ} \mathrm{C}$ for $45 \mathrm{~s}$, and $72^{\circ} \mathrm{C}$ for $1 \mathrm{~min}$; with a final extension of $10 \mathrm{~min}$ at $72^{\circ} \mathrm{C}$. The PCR assay was carried out in a $20-\mu l$ reaction volume with $50 \mathrm{ng}$ of genomic DNA and deoxynucleotide triphosphates at $0.25 \mathrm{mmol} /$ liter, $\mathrm{MgCl}_{2}$ at $1.0 \mathrm{mmol} /$ liter, each primer at $0.5 \mu \mathrm{mol} /$ liter, 1:10 diluted Qiagen PCR buffer, and $1 \mathrm{U}$ of Taq DNA polymerase (Qiagen) in a T-100 thermal cycler (Bio-Rad). Amplification products were separated by electrophoresis in $1 \%$ agarose gel (Eppendorf) and purified using the QIAquick PCR Purification Kit (Qiagen) before being sequenced by BMR-Genomics. BLASTn analysis of the sequences was carried out to identify each isolate.

\section{Results}

Validation of the LAMP assays. The specificity of the F. fujikuroi and $M$. oryzae amplicons was checked against the National Center for Biotechnology Information nucleotide database using BLASTn, which showed a $100 \%$ identity with the GenBank sequence accessions KT257540.1 and KM485261.1, respectively. The LAMP assays developed for $F$. fujikuroi and $M$. oryzae were validated according to EPPO standard PM7/98. When tested with an inclusivity and exclusivity panel of fungal isolates, amplification was not detected in any DNA sample from nontarget species (Supplementary Table S1). The average Tp for the $F$. fujikuroi LAMP assay, using DNA concentrations of 1 to $30 \mathrm{ng} / \mu \mathrm{l}$, ranged from 18 to $22 \mathrm{~min}$ with an annealing temperature ranging from 87.97 to $88.38^{\circ} \mathrm{C}$, while the Tp for the $M$. oryzae LAMP assay ranged from 13 to $16 \mathrm{~min}$ with an annealing temperature of 88.41 to $89^{\circ} \mathrm{C}$.

The specificity of the assays was compared with the published real-time PCR (TaqMan) for each assay. None of the nontargets amplified with the $M$. oryzae real-time PCR assay; however, nonspecific amplifications were recorded for several Fusarium spp. (Amaral Carneiro et al. 2017; Su'udi et al. 2013) using the F. fujikuroi real-time PCR assay.

The sensitivity of both assays was tested using several different approaches (Figs. 1 and 2). The lowest quantity of DNA amplified using the $F$. fujikuroi LAMP assay corresponds to an amount of DNA ranging between 100 and $999 \mathrm{fg}$ (270 fg for strain C1, $23.1 \mathrm{fg}$ for strain CsSP1, 3.06 pg for strain CsAg3, and 61.8 pg for strain VPG2), 
while the $M$. oryzae LAMP assay amplified DNA ranging between 10 and $99 \mathrm{pg}$ (13.7 pg for strain Guy11 and $183 \mathrm{pg}$ for strain AG0043). The same 10-fold serial dilutions of DNA were simultaneously tested by means of qPCR; for $F$. fujikuroi, the qPCR assay amplified DNA amounts ranging between 100 and $999 \mathrm{fg}$ and the $M$. oryzae assay amplified DNA ranging between 1 and $9.9 \mathrm{pg}$.

The sensitivity was also checked by using individual rice seeds inoculated with 10-fold serial dilutions of both pathogens, then extracting the DNA with the crude extraction method and a commercial DNA extraction kit. The results of these tests are reported in Figure 3. The LAMP assay for $F$. fujikuroi repeatedly (in all replicates) detected the two first serial dilutions $\left(2 \times 10^{5}\right.$ and $\left.2 \times 10^{4} \mathrm{CFU} / \mathrm{ml}\right)$, while the other dilutions were detected with Tp results in excess of $35 \mathrm{~min}$, which was considered the time threshold of the LAMP test (data not shown). The M. oryzae LAMP assay could be used to repeatedly (in all replicates) detect the first serial dilution $\left(3.3 \times 10^{3}\right.$ cells $\left./ \mathrm{ml}\right)$, whereas only some replicates of the dilution $3.3 \times 10^{2}$ cells $/ \mathrm{ml}$ were detected.

For both assays, DNA from the individual seeds was extracted using crude and commercial kit extraction and amplified with qPCR, confirming the inoculum. The qPCR quantification showed that the individual seeds inoculated with $M$. oryzae at $3.3 \times 10^{3} \mathrm{CFU} / \mathrm{ml}$ had an average of 3,900 cells, whereas the individual seeds inoculated with $F$. fujikuroi at $2 \times 10^{5} \mathrm{CFU} / \mathrm{ml}$ had 102 cells. However, both qPCR were not repeatable; only one or two biological replicates of the five tested amplified with the commercial kit while, with the crude extraction, the qPCR did not produce any amplification.

In contrast, positive amplification was obtained for the assays with both kit and crude extraction methods using LAMP, although a slight variation of the positive amplification was reported, and a faster detection was obtained with the kit extraction method in the lowest

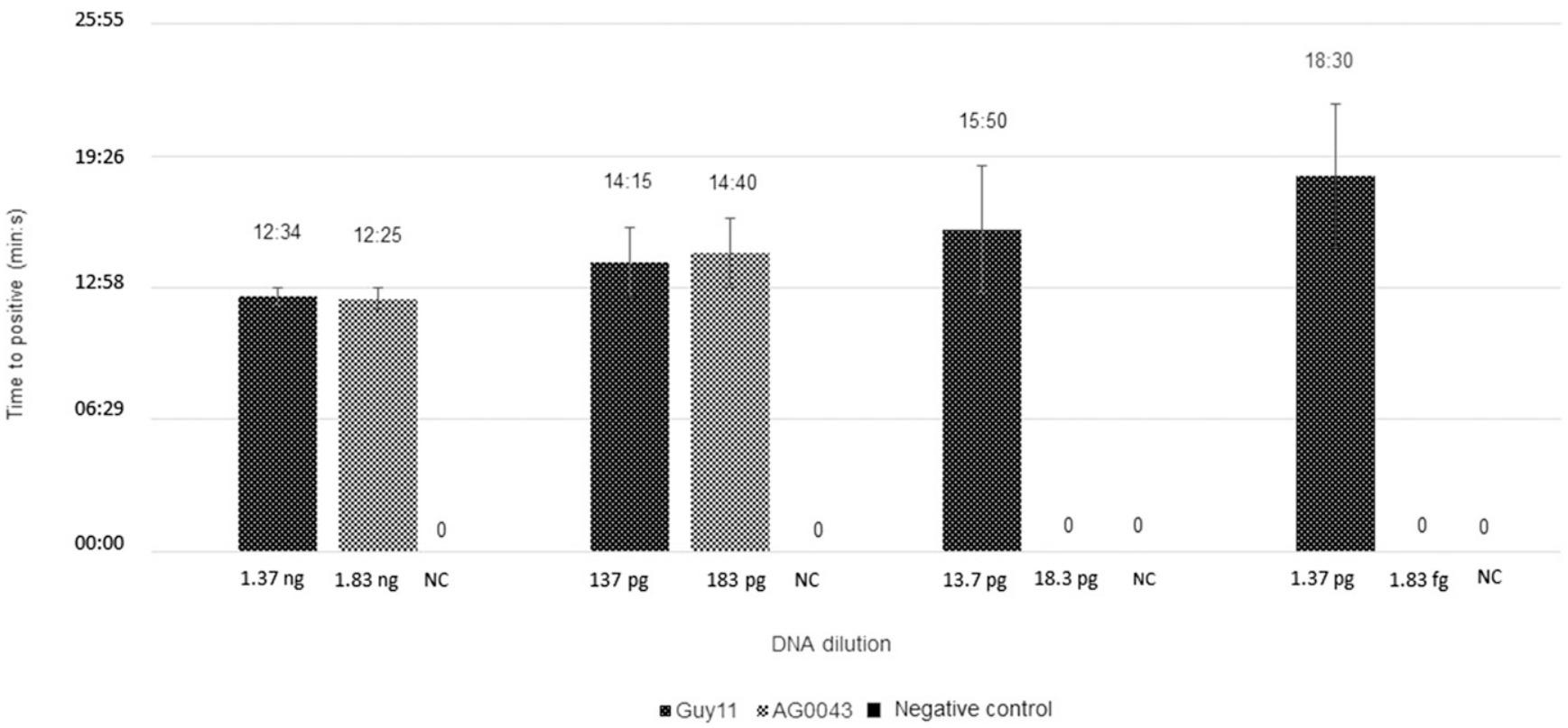

Fig. 1. Sensitivity test using 10-fold serial dilutions of the DNA of two Magnaporthe oryzae isolates, where the average time to positive of two isolates in three independent assays is reported for each isolate. Negative control (with water) and positive control (with DNA from the fungi from this study) were included in each run.

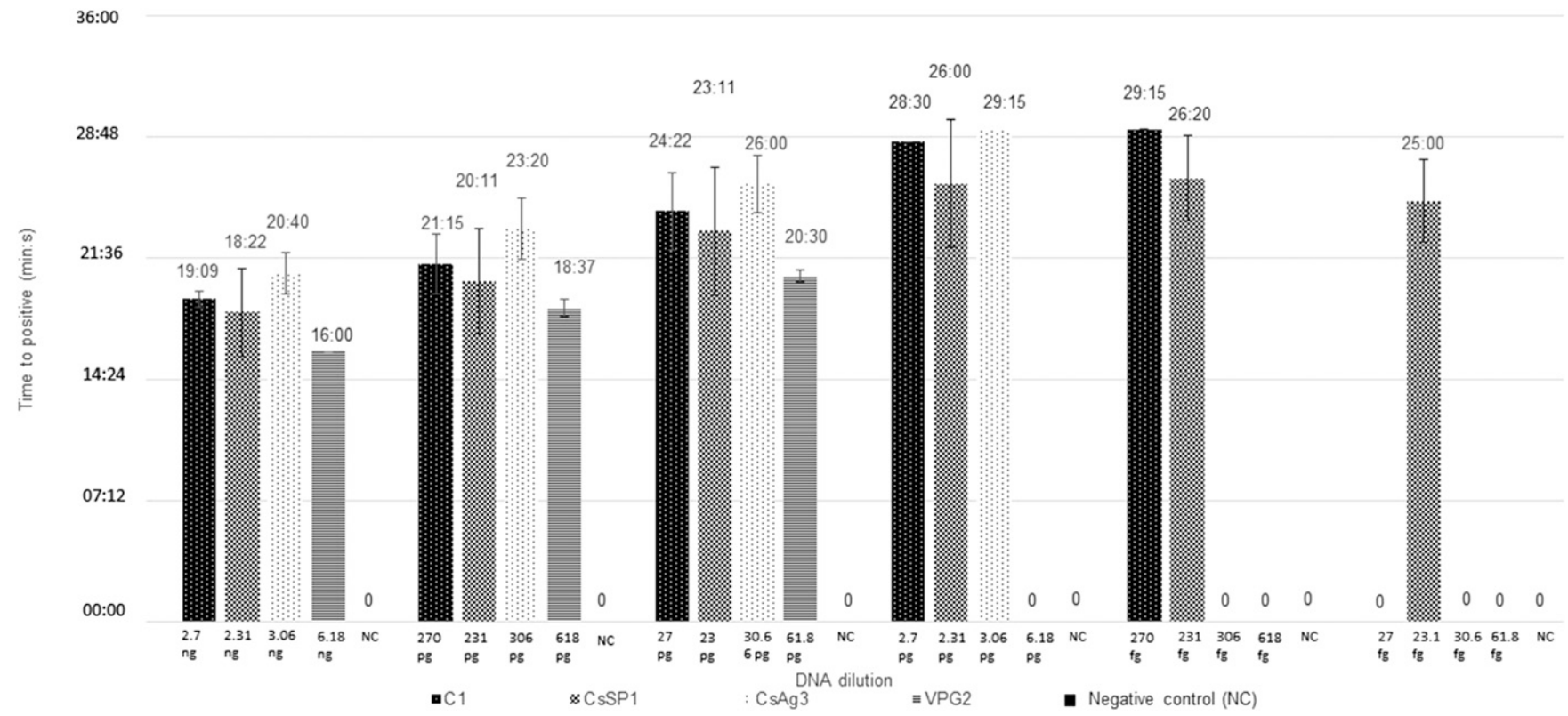

Fig. 2. Sensitivity test using a 10 -fold serial dilution of the DNA of four Fusarium fujikuroi isolates, where the average of three replicates of time to positive of four isolates tested in three independent assays is reported for each isolate. Negative control (with water) and positive control (with DNA from the fungi from this study) were included in each run. 
dilution for the $F$. fujikuroi assay (from $34 \mathrm{~min} 10 \mathrm{~s}$ to $29 \min 37 \mathrm{~s}$, respectively) (Figs. 3 and 4 ) and in the two serial dilutions of M. oryzae (from $15 \mathrm{~min} 50 \mathrm{~s}$ to $13 \mathrm{~min} 35 \mathrm{~s}$ for the highest dilution and 36 min $43 \mathrm{~s}$ to $33 \mathrm{~min} 21 \mathrm{~s}$ for the lowest dilution).

Based on the positive results obtained for the individual seed testing, batches of 15 and 25 rice seeds, including different concentrations of infected seed inoculated with $F$. fujikuroi at $2 \times 10^{5}$ and $2 \times 10^{4}$ $\mathrm{CFU} / \mathrm{ml}$ and $M$. oryzae at $3.3 \times 10^{3} \mathrm{CFU} / \mathrm{ml}$, were used to determinate the detectable infection rate of a batch. The most repeatable and reliable results obtained using infected seed inoculated with F. fujikuroi at $2 \times 10^{5} \mathrm{CFU} / \mathrm{ml}$ corresponded to a $33.3 \%$ infection rate, while an $8 \%$ infection rate was detected in all batches and replicates,

\begin{tabular}{|c|c|c|c|c|c|c|c|}
\hline \multirow{2}{*}{$\mathbf{A}$} & & \multicolumn{2}{|c|}{ AVERAGE } & \multicolumn{2}{|c|}{ AVERAGE } & \multicolumn{2}{|c|}{ AVERAGE } \\
\hline & & $T p(\min : s)$ & Anneal ${ }^{\circ} \mathrm{C}$ & $T p(\min : s)$ & Anneal ${ }^{\circ} \mathrm{C}$ & $T p(\min : s)$ & Anneal ${ }^{\circ} \mathrm{C}$ \\
\hline \multirow{6}{*}{$2 \times 10^{5} \mathrm{CFU} / \mathrm{ml}$} & 1stseed & $30: 20 \pm 05: 08$ & $85.79 \pm 1.19$ & $26: 40 \pm 00: 35$ & $86.89 \pm 0.72$ & $28: 30 \pm 05: 00$ & $84.94 \pm 0.56$ \\
\hline & 2ndseed & $17: 50 \pm 01: 11$ & $87.35 \pm 1.64$ & $30: 10 \pm 02: 08$ & $86.69 \pm 0.64$ & $34: 05 \pm 03: 13$ & $81.63 \pm 1.42$ \\
\hline & 3rd seed & $19: 00 \pm 01: 18$ & $86.74 \pm 0.12$ & $27: 30 \pm 01: 18$ & $87.31 \pm 0.14$ & $32: 45 \pm 01: 09$ & $82.49 \pm 0.76$ \\
\hline & 4th seed & $25: 05 \pm 02: 59$ & $83.69 \pm 2.2$ & & & $32: 35 \pm 00: 35$ & $82.36 \pm 1.35$ \\
\hline & 5 th seed & $22: 15 \pm 06: 30$ & $86.03 \pm 1.45$ & & & $33: 15: 00$ & $81.59 \pm 0.49$ \\
\hline & AVERAGE & $22: 54 \pm 05: 02$ & $85.92 \pm 1.39$ & $28: 07 \pm 01: 50$ & $86.96 \pm 0.32$ & $32: 14 \pm 02: 10$ & $82.6 \pm 1.37$ \\
\hline \multirow{7}{*}{$2 \times 10^{4} \mathrm{CFU} / \mathrm{ml}$} & 1stseed & $28: 45 \pm 04: 20$ & $86.01 \pm 0.71$ & $31: 07 \pm 00: 32$ & $87.365 \pm 0.11$ & $27: 55 \pm 04: 58$ & $85.07 \pm 0.35$ \\
\hline & 2nd seed & $33: 05 \pm 07: 55$ & $85.49 \pm 1.37$ & $29: 25 \pm 00: 17$ & $87.03 \pm 0.94$ & $34: 20 \pm 02: 22$ & $82.76 \pm 0.43$ \\
\hline & 3rd seed & $46: 00: 00$ & 85.61 & $28: 20 \pm 01: 53$ & $86.89 \pm 0.21$ & $32: 05 \pm 01: 23$ & $82.47 \pm 0.93$ \\
\hline & & & & & & & \\
\hline & 4th seed & $07: 25 \pm 01: 01$ & $85.98 \pm 0.2$ & & & $35: 10 \pm 00: 38$ & $81.99 \pm 1.54$ \\
\hline & 5th seed & $35: 35 \pm 06: 02$ & $84.87 \pm 1.36$ & & & $37: 45 \pm 03: 33$ & $81.98 \pm 1.03$ \\
\hline & AVERAGE & $34: 10 \pm 07: 23$ & $85.64 \pm 0.46$ & $29: 37 \pm 01: 24$ & $87.08 \pm 0.24$ & $33: 27 \pm 03: 42$ & $82.85 \pm 1.29$ \\
\hline
\end{tabular}

B

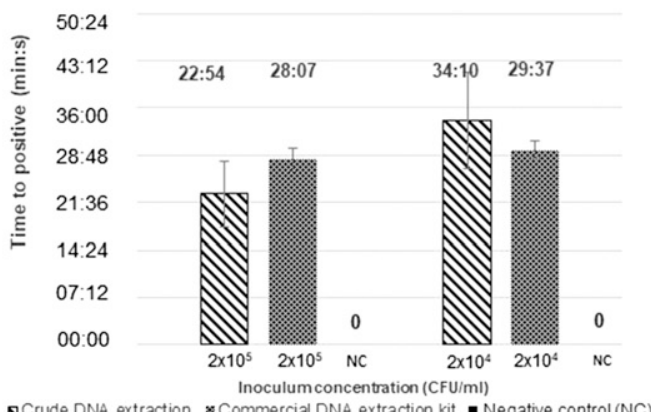

s Crude DNA extraction $\approx$ Commercial DNA extraction kit - Negative control (NC)

Fig. 3. A, Results of the sensitivity test of the Fusarium fujikuroi loop-mediated isothermal amplification (LAMP) assay in which individual rice seeds were used and the DNA was extracted using a crude extraction method and a kit extraction method in triplicate. A cytochrome oxidase (COX) LAMP assay was included as an internal control of the DNA extraction. The table lists the time to positive (Tp) and the annealing temperature (Anneal) on average, considering only positive amplification results with a Tp of less than $35 \mathrm{~min}$. B, The bar graph represents the differences between the Tp obtained using both types of DNA extraction methods and the different inoculum concentrations. Negative control (with water) and positive control (with DNA from the fungi from this study) were included in each run.

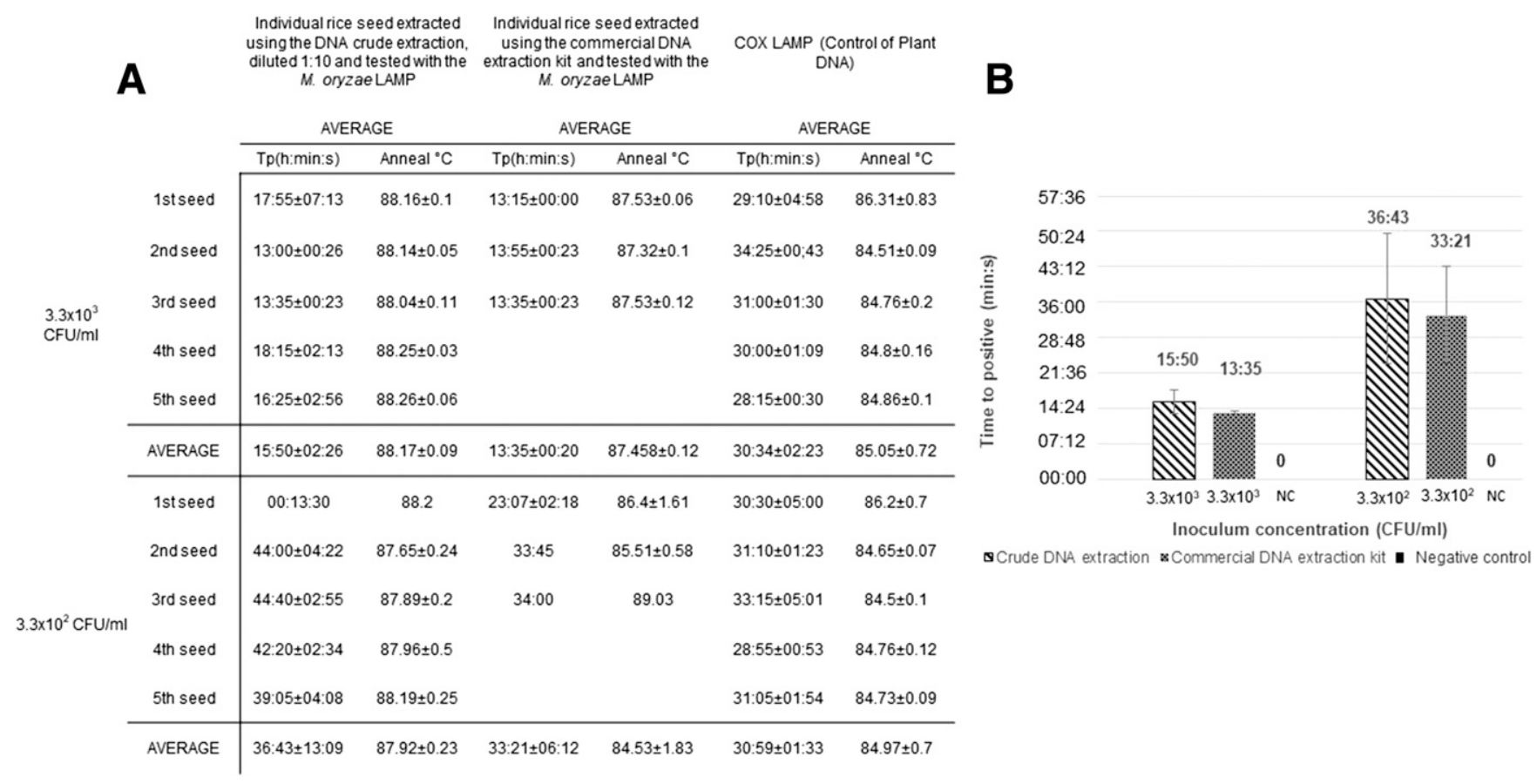

Fig. 4. A, Sensitivity of the Magnaporthe oryzae loop-mediated isothermal amplification (LAMP) assay with individual rice seeds, where DNA was extracted using crude and kit extraction methods in triplicate. A cytochrome oxidase (COX) LAMP assay was included as internal control of the DNA extraction. The table lists the time to positive (Tp) and the annealing temperature (Anneal) on average, considering only positive amplification results with a Tp of less than $35 \mathrm{~min}$. B, The bar graph represents the differences between the Tp obtained using both types of DNA extraction method and the different inoculum concentrations. Negative control (with water) and positive control (with DNA from the fungi from this study) were included in each run. 
with variations in the positive time amplification among replicates (Fig. 5 ). The best result obtained from the batches with the seed inoculated with $F$. fujikuroi at $2 \times 10^{4} \mathrm{CFU} / \mathrm{ml}$ corresponds to a $33.3 \%$ infection rate but the results were not repeated. These results indicate that the batches with a $33.3 \%$ infected rate can be detected regardless of the concentration of the pathogen in the seed. The best results of the M. oryzaeinfected seed were obtained for the 8 and $13.3 \%$ infection rate batches. The batches used for the kit extraction produced more repeatable results, obtaining positive amplification in all of the LAMP replicates. (Fig. 6).

Identity of LAMP products for $\boldsymbol{F}$. fujikuroi. The specificity of the $F$. fujikuroi LAMP assay was checked by means of enzyme DNA restriction, using the $M s p I$ and $P v u I$ enzymes, and the same pattern was obtained for all of the samples (pure DNA and crude samples), even with products that gave different annealing temperatures
(Fig. 7). Further exploration demonstrated that the crude seed extracts influenced the annealing temperature of more than $1^{\circ} \mathrm{C}$ for each dilution (Table 2).

Testing naturally infected rice. Five seed batches were tested to compare the traditional culture method of 400 seeds with the LAMP assay implemented using two different DNA extraction techniques.

The results of the cultivation test showed that rice cultivars Deneb, Selenio, and Galileo were naturally infected with $M$. oryzae at 0.01 , 0.01 , and $0.005 \%$, respectively, whereas Carnise and Dorella were free of this pathogen (data not shown). On the other hand, the PDA test showed that Deneb, Carnise, and Selenio were naturally infected with $F$. fujikuroi at $0.075,0.025$, and $0.025 \%$ infection rates, respectively, while Dorella and Galileo were not infected with $F$. fujikuroi. Seed from Deneb were the most infected with $F$. fujikuroi, producing a large number of colonies of this pathogen.
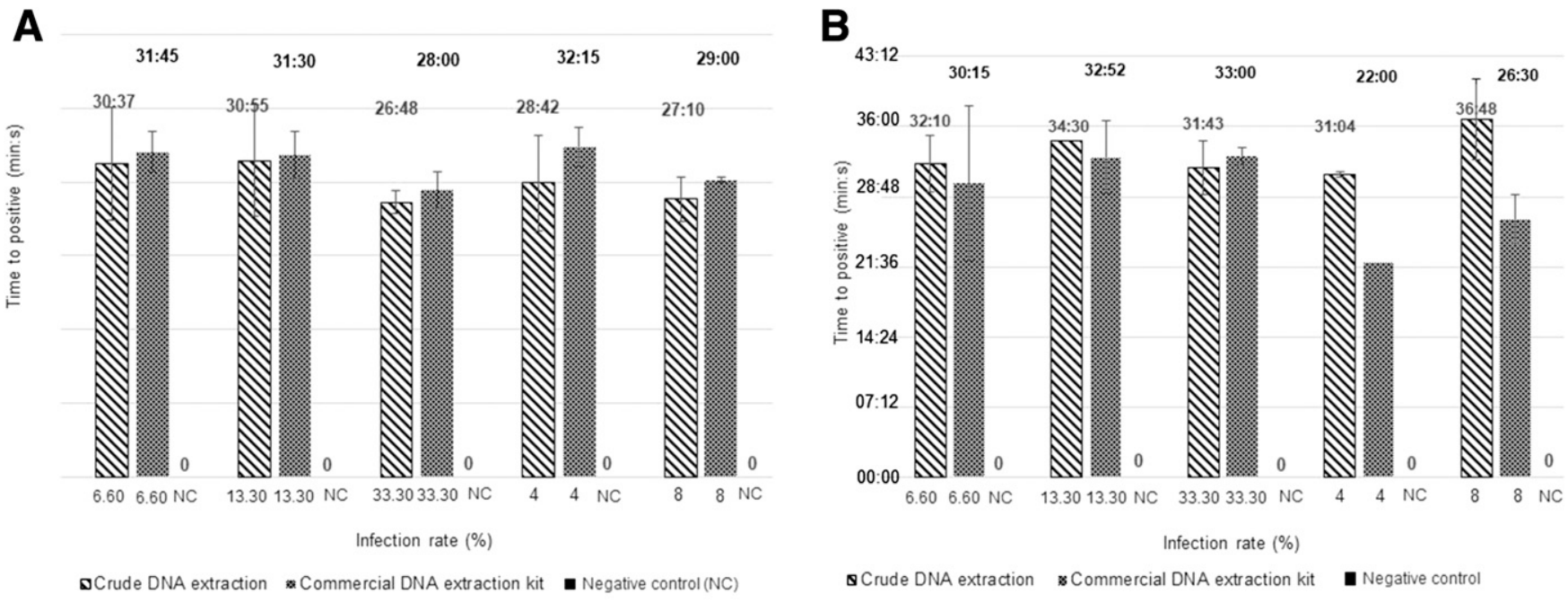

$6.60 \%$

Fig. 5. Sensitivity of the Fusarium fujikuroi loop-mediated isothermal amplification assay with rice seed batches with different percentages of infected seed, where DNA was extracted using crude and kit extraction methods in triplicate. Average and standard deviation of the time to positive of three replicates are reported, according to the DNA extraction method used. Negative control (with water) and positive control (with DNA from the fungi from this study) were included in each run. Bar graphs represent inoculum concentrations of $\mathrm{A}, 2 \times 10^{5} \mathrm{CFU} / \mathrm{ml}$ and $\mathrm{B}, 2 \times 10^{4} \mathrm{CFU} / \mathrm{ml}$.

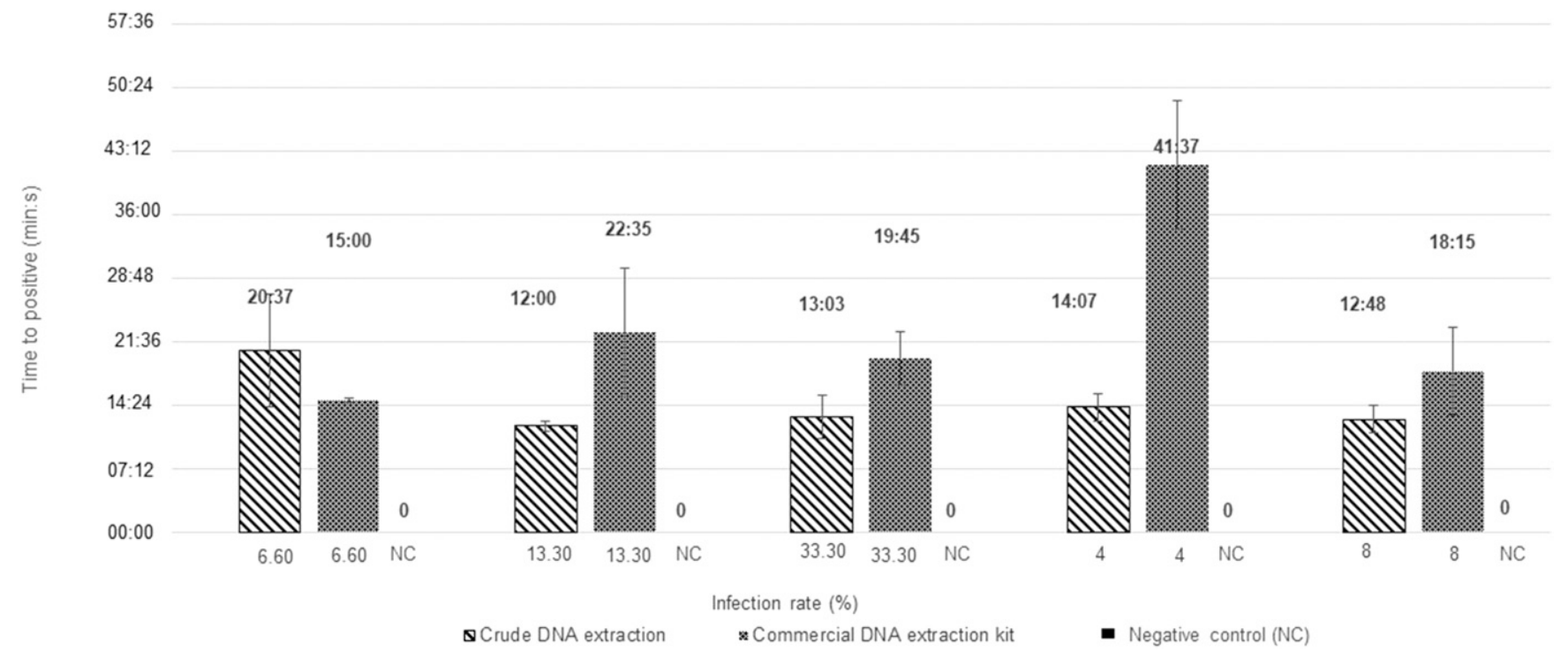

Fig. 6. Sensitivity of the Magnaporthe oryzae loop-mediated isothermal amplification assay with rice seed batches with different percentages of infected seed, where DNA was extracted using crude and kit extraction methods in triplicate. Average and standard deviation of the time to positive of three replicates are reported, according to the DNA extraction method used. Negative control (with water) and positive control (with DNA from the fungi from this study) were included in each run. 
A number of colonies $(n=8)$ were tested using DNA barcoding and the results of the BLASTn analysis confirmed the Fusarium sp. as F. fujikuroi. An example sequence was deposited in GenBank with the accession numbers MF677976, MF677977, MF677978, MF677979, MF677980, MF677981, MF677982, and MF677983.

The results of testing batches of seed using the LAMP assays confirmed the blotter results. When testing for M. oryzae, seed from the Deneb, Selenio, and Galileo gave positive results. The number of positive results varied depending on the cultivar tested using both types of DNA extraction method. More positive results were found for Deneb, followed by Selenio and Galileo. The commercial DNA extraction kit gave more positive results ( 28 of 48,15 of 48 , and 9 of 48 for Deneb, Selenio, and Galileo, respectively) than the crude DNA extraction method (7 of 48, 2 of 48, and 3 of 48 for Deneb, Selenio, and Galileo, respectively) (Table 3 ).

The LAMP for F. fujikuroi also confirmed the blotter test, confirming the presence of the fungi in Deneb, Carnise, and Selenio. However, for Fusarium spp., only the DNA from the commercial DNA extraction kit produced positive amplification, whereas the crude extracted DNA was not detected in any of the rice cultivars tested (Table 4).

\section{Discussion}

Two LAMP assays have been developed in this work to obtain a simple, fast, and cheap diagnostic method for screening rice seed for the presence of the pathogens $F$. fujikuroi and M. oryzae. Currently, the method recommended by the International Rules for Seed Testing 2017 (ISTA; http://www.bibme.org/citation-guide/apa/website/) consists of blotting a working sample of 400 seeds divided into 25 -seed subsamples onto a 90 -mm filter paper soaked with distilled water and recording the percentage of infected seed for 7 days at $22^{\circ} \mathrm{C}$ in alternating 12 -h cycles of light and darkness, confirmed by stereoscopic examination of each seed. Despite the ease of the blotting method and the extensive use in diagnostic laboratories, a correct screening requires trained diagnosticians who are able to identify the conidia of the resulting fungal growth under a stereoscopic microscope. One of the aspects that should be taken into account during this activity is the presence of other conidia with similar morphological features, which may be misidentified as rice blast, such as the saprophytic fungi Cladosporium spp. (ISTA 2018). A misidentification can lead to economic losses for any company that is attempting to certify the absence of pathogens in rice seed. The other disadvantage of the blotting method is the long incubation of 7 days. This also requires sizable and expensive controlled-environment chambers to perform the tests.

PCR-based methods are often used in well-equipped laboratories to carry out routine identification tests. However, the complexity of time-consuming PCR-based methods reduces the possibility of on-site sampling and detection, thus increasing the delay between sampling (process) and results. One of the drawbacks of the PCRbased method is its sensitivity to inhibitors, which can modify the specificity and even produce false-negative results. To avoid this problem, the PCR is combined with long extraction methods to obtain high-quality nucleic acids from the sampled material (Boonham et al. 2008). These inhibitors are a heterogeneous group of poorly characterized compounds, including phenols, polysaccharides, melanin, humic or tannic acids, and proteins present in rice seed (Schrader et al. 2012; Tian et al. 2004). The LAMP assay shows optimal characteristics, because it allows rapid, sensitive, specific, and easy field detection and is potentially less sensitive to inhibitors (Kaneko et al. 2007).

A LAMP assay for $M$. oryzae has been recently developed by Villari et al. (2017) for the detection of airborne inoculum in turfgrass. However this LAMP assay was not tested on M. oryzae isolated from Oryza sativa, unlike the test presented here, which was able to amplify the DNA of $M$. oryzae in less than $20 \mathrm{~min}$. The $F$. fujikuroi LAMP assay developed in this study was found to be more specific than the previously published real-time PCR assay (Amaral Carneiro et al. 2017). The sensitivity of the LAMP assays was validated for both DNA samples and in vivo samples, obtaining consistent and reproducible results using batches of 25 rice seeds with different infection rates. Although both published real-time PCR were reported to be more sensitive than the so-far-developed LAMP assays, neither of them produced reproducible results using rice seed.

During the development, it was noted that the annealing temperature of the $F$. fujikuroi LAMP assay was affected by the addition of crude extracts of rice seed. Although the annealing temperature was affected, the amplification itself was not adversely affected. Restriction digests demonstrated the specificity of the amplified products in the presence of seed extracts despite the variation in the annealing temperature observed.

The reliability of both LAMP assays using commercial rice seed samples was assessed by comparing them to the traditional blotting test recommended by ISTA (ISTA 2018) with five different rice

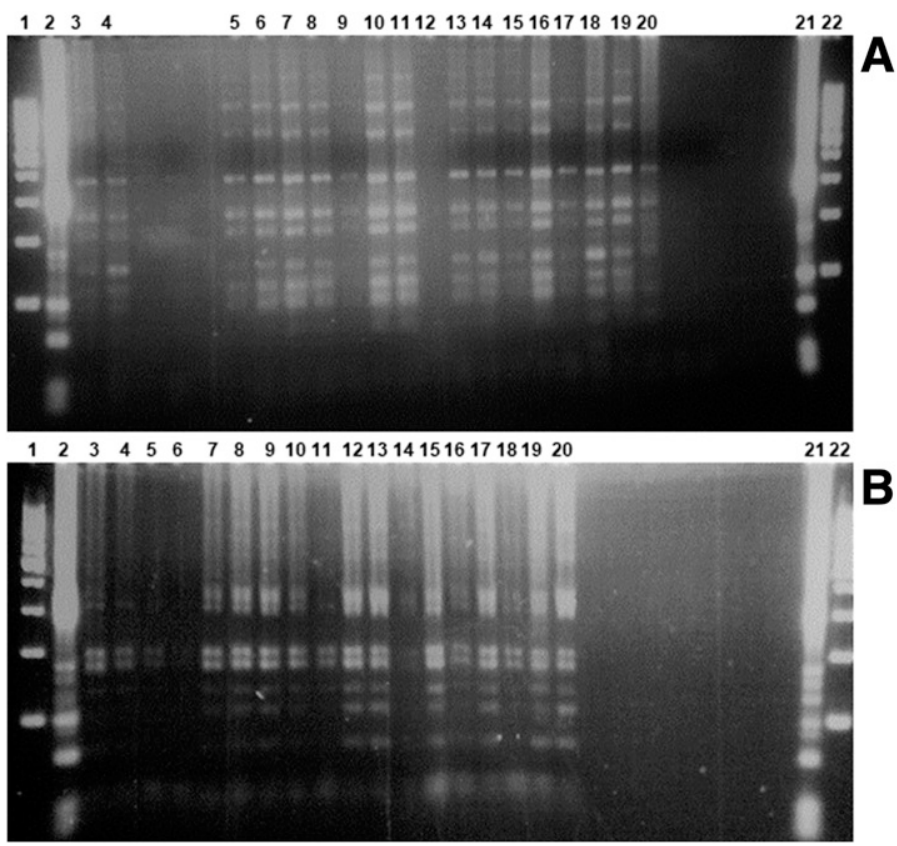

\begin{tabular}{ccc}
\hline Lane & Sample & $\begin{array}{c}\text { Annealing } \\
\text { temperature }\left({ }^{\circ} \mathrm{C} \text { ) }\right.\end{array}$ \\
\hline 1 & GeneRuler 100bp (Thermo Scientific) & \\
\hline 2 & LAMP F. fujikuroi CsC8 (Not digested) & 88.20 \\
3 & Twenty-five rice seed extraction & 87.90 \\
4 & Twenty-five rice seed extraction & 87.85 \\
5 & Twenty-five rice seed extraction & 87.14 \\
6 & Twenty-five rice seed extraction & 86.94 \\
7 & Twenty-five rice seed extraction & 86.89 \\
8 & Twenty-five rice seed extraction & 86.93 \\
9 & Twenty-five rice seed extraction & 86.39 \\
10 & LAMP F. fujikuroi CsC8 (Not digested) & 88.20 \\
11 & LAMP F fujikuroi CsC8 (Not digested) & 88.35 \\
12 & Twenty-five rice seed extraction & 83.65 \\
13 & Twenty-five rice seed extraction & 86.42 \\
14 & Twenty-five rice seed extraction & 86.42 \\
15 & Twenty-five rice seed extraction & 82.35 \\
16 & Twenty-five rice seed extraction & 85.91 \\
17 & Twenty-five rice seed extraction & 83.01 \\
18 & Twenty-five rice seed extraction & 86.51 \\
19 & LAMP F. fujikuroi CsC8 (Digested) & 88.31 \\
20 & LAMP F. fujikuroi CsC8 (Digested) & 88.31 \\
21 & LAMP F fujikuroi CsC8 (Not digested) & 88.20 \\
\hline 22 & GeneRuler 100bp (Thermo Scientific) & \\
\hline & &
\end{tabular}

Fig. 7. A, Mspl and B, Pvul digestions of the different loop-mediated isothermal amplification (LAMP) products. Undigested LAMP assay product of Fusarium fujikuroi CsC8 was included as control. The table reports the lane and the annealing temperature of each sample tested. 
cultivars. Other LAMP assays have been developed to test cereal seed but, in these methods, the DNA is extracted with an electric grinder (Abd-Elsalam et al. 2011), thus making on-site detection difficult. We explored the potential of the crude extraction method developed by Tomlinson et al. (2010b), which is based on alkaline lysis combined with manual shaking, for testing rice seed in the present study. This method has the potential for achieving results directly on site as a screening tool for seed batches, or could become a quick and easy detection tool in the laboratory without expensive equipment and time-consuming DNA extraction.

The reliability of both assays was improved when a commercial DNA extraction kit was used, presumably due to an improvement in the sensitivity of the tests. In conjunction with the commercial extraction kit, both LAMP assays may become a potential routine test for the detection of $F$. fujikuroi and $M$. oryzae in rice seed, especially due to the improved turnaround time to perform the experiment (some hours) against the 7 days of a blotting method. The $M$. oryzae LAMP assay gave the same results as the blotter test when using the crude extraction which would ensure a quicker result, perhaps as a screening test performed in the field. However, a laboratory confirmation test using a commercial DNA extraction kit may be needed for negative results.

Table 2. Annealing temperature of the loop-mediated isothermal amplification (LAMP) product of Fusarium fujikuroi strain CsC8 twofold serial diluted with and without seed extracts

\begin{tabular}{lcc}
\hline & \multicolumn{2}{c}{ Annealing temperature $\left({ }^{\circ} \mathbf{C}\right)$ from LAMP product } \\
\cline { 2 - 3 } CsC8 DNA & Without seed extracts & With $\mathbf{~} \boldsymbol{\mu l}$ of seed extract \\
\hline LAMP product & 87.36 & 86.05 \\
Dilution -2 & 87.00 & 85.50 \\
Dilution -4 & 87.00 & 86.14 \\
Dilution -6 & 87.10 & 86.34 \\
Dilution -8 & 87.19 & 85.94 \\
Dilution -10 & 75.11 & 73.97 \\
Dilution -12 & 75.41 & 73.42 \\
Dilution -14 & 75.31 & 74.22 \\
\hline
\end{tabular}

Table 3. Results of testing 400 seed batches of five cultivars in 25 -seed subsample batches using the Magnaporthe oryzae loop-mediated isothermal amplification assay representing average cycle threshold values for the positive seed batches extracted using each of the two DNA extraction methods

\begin{tabular}{lccccc}
\hline & \multicolumn{3}{c}{$\begin{array}{c}\text { Commercial DNA extraction } \\
\text { kit }\end{array}$} & & \multicolumn{2}{c}{ Crude DNA extraction } \\
\cline { 2 - 3 } \cline { 5 - 6 } Cultivar & $\mathbf{T p}^{\mathbf{a}}$ (min:s) & Anneal $\left({ }^{\circ} \mathbf{C}\right)$ & & $\mathbf{T p}^{\mathbf{a}}$ (min:s) & Anneal $\left({ }^{\circ} \mathbf{C}\right)$ \\
\hline Deneb & $15: 57 \pm 03: 51$ & $89.18 \pm 1.64$ & & $17: 30 \pm 07: 23$ & $89.2 \pm 0.19$ \\
Selenio & $15: 72 \pm 04: 14$ & $89.27 \pm 0.11$ & & $19: 21 \pm 07: 34$ & $89.21 \pm 0.22$ \\
Galileo & $15: 38 \pm 02: 22$ & $89.04 \pm 0.17$ & & $19: 49 \pm 01: 50$ & $88.85 \pm 0.61$ \\
Dorella & 0 & 0 & & 0 & 0 \\
Carnise & 0 & 0 & & 0 & 0 \\
\hline
\end{tabular}

${ }^{\mathrm{a}} \mathrm{Tp}=$ time to positive.

Table 4. Results of testing 400 seed batches of five cultivars in 25-seed subsample batches using the Fusarium fujikuroi loop-mediated isothermal amplification assay representing average cycle threshold values for the positive seed batches extracted using each of the two DNA extraction methods

\begin{tabular}{lccccc}
\hline & \multicolumn{2}{c}{$\begin{array}{c}\text { Commercial DNA extraction } \\
\text { kit }\end{array}$} & & \multicolumn{2}{c}{ Crude DNA extraction } \\
\cline { 2 - 3 } Cultivar & $\mathbf{T p}^{\mathbf{a}}$ (min:s) & Anneal $\left({ }^{\circ} \mathbf{C}\right)$ & & $\mathbf{T p}^{\mathbf{a}}$ (min:s) & Anneal $\left({ }^{\circ} \mathbf{C}\right)$ \\
\hline Galileo & 0 & 0 & & 0 & 0 \\
Dorella & 0 & 0 & & 0 & 0 \\
Deneb & $25: 91 \pm 04: 04$ & $88.11 \pm 0.46$ & & 0 \\
Carnise & $29: 91 \pm 02: 87$ & $88.14 \pm 0.6$ & & 0 & 0 \\
Selenio & $33: 76 \pm 04: 06$ & $88.24 \pm 0.38$ & & 0 & 0 \\
\hline
\end{tabular}

a $\mathrm{Tp}=$ time to positive.
In order to ensure the DNA extraction from rice seed and interpret the negative results from false negatives, the use of a LAMP assay, based on cytochrome oxidase, may be a useful indicator, because it is able to distinguish between a failed acid nucleic extraction and the negative presence of the pathogen in samples (Tomlinson et al. 2010a).

In summary, two LAMP assays have here been designed for $F$. fujikuroi and $M$. oryzae and validated according to an international validation standard published by EPPO (PM7/98). They have been found to be sufficiently sensitive and specific to provide a viable and rapid alternative to the current morphological identification methods. Furthermore, when the LAMP assays were used on Genie II or Genie III platforms (OptiGene Ltd.), they are a rapid (less than $1 \mathrm{~h}$ ) way of testing the pathogen levels in batches of rice seed in order to facilitate correct preventive and control measures before pathogen dispersal.

\section{Acknowledgments}

We thank D. Tharreau (Mixte de Recherche, Biologie et Génétique des Interactions Plante-Parasite) for providing the Magnaporthe and Pyricularia spp. isolates.

\section{Literature Cited}

Abd-Elsalam, K., Bahkali, A., Moslem, M., Amin, O. E., and Niessen, L. 2011. An optimized protocol for DNA extraction from wheat seeds and Loop-Mediated Isothermal Amplification (LAMP) to detect Fusarium graminearum contamination of wheat grain. Int. J. Mol. Sci. 12:3459-3472.

Amaral Carneiro, G., Matic, S., Ortu, G., Garibaldi, A., Spadaro, D., and Gullino, M. L. 2017. Development and validation of a TaqMan real time PCR assay for the specific detection and quantification of Fusarium fujikuroi in rice plants and seeds. Phytopathology 107:885-892.

Amatulli, M. T., Spadaro, D., Gullino, M. L., and Garibaldi, A. 2012. Conventional and real-time PCR for the identification of Fusarium fujikuroi and Fusarium proliferatum from diseased rice tissues and seeds. Eur. J. Plant Pathol. 134:401-408.

Bashyal, B. M., Aggarwal, R., Banerjee, S., Gupta, S., and Sharma, S. 2014 Pathogenicity, ecology and genetic diversity of the Fusarium spp. Associated with an Emerging bakanae Disease of Rice (Oryza sativa L.) in India. Pages 307-314 in: Microbial Diversity and Biotechnology in Food Security. R. Kharwar, R. Upadhyay, N. Dubey, and R. Raghuwanshi, eds. Springer India, New Delhi.

Boonham, N., Glover, R., Tomlinson, J., and Mumford, R. 2008. Exploiting generic platform technologies for the detection and identification of plant pathogens. Pages 355-363 in: Sustainable Disease Management in a European Context. D. B. Collinge, L. Munk, and B. M. Cooke, eds. Springer Netherlands, Dordrecht, The Netherlands.

Chataigner, J. 1996. Rice diseases in the Mediterranean region and the possibilities of breeding for resistance. Pages 15-17 in: Proc. Montpellier Semin. Cahiers Options Méditerranéennes, Montpellier, France.

Choi, J., Park, S. Y., Kim, B. R., Roh, J. H., Oh, I. S., Han, S. S., and Lee, Y. H. 2013. Comparative analysis of pathogenicity and phylogenetic relationship in Magnaporthe grisea species complex. PLoS One 8:e57196.

Chomczynski, P., and Rymaszewski, M. 2006. Alkaline polyethylene glycolbased method for direct PCR from bacteria, eukaryotic tissue samples, and whole blood. Biotechniques 40:454-458

Delseny, M., Salses, J., Cooke, R., Sallaud, C., Regad, F., Lagoda, P., Guiderdoni, E., Ventelon, M., Brugidou, C., and Ghesquièrec, A. 2001. Rice genomics: Present and future. Plant Physiol. Biochem. 39:323-334.

Du Toit, L. J. 2004. Management of diseases in seed crops. Pages 675-677 in: Encyclopedia of Plant and Crop Science. R. Goodman, ed. Marcel Dekker, New York.

Geiser, D. M., Jiménez-Gasco, M. D. M., Kang, S., Makalowska, I., Veeraraghavan, N., Ward, T. J., Zhang, N., Kuldau, G. A., and O'Donnell, K. 2004. FUSARIUM-ID v. 1.0: A DNA sequence database for identifying Fusarium. Eur. J. Plant Pathol. 110:473-479.

Goto, M., Honda, E., Ogura, A., Nomoto, A., and Hanaki, K. I. 2009. Colorimetric detection of loop-mediated isothermal amplification reaction by using hydroxy naphthol blue. Biotechniques 46:167-172.

Hodgetts, J., Karamura, G., Johnson, G., Hall, J., Perkins, K., Beed, F., Nakato, V., Grant, M., Studholme, D. J. Boonham, N., and Smith, J. 2015. Development of a lateral flow device for in-field detection and evaluation of PCR-based diagnostic methods for Xanthomonas campestris pv. musacearum, the causal agent of banana Xanthomonas wilt. Plant Pathol. 64:559-567.

Hodgetts, J., Tomlinson, J., Boonham, N., Gonzlzález-Martín, I., Nikolić, P., Swarbrick, P., Yankey, E. N., and Dickinson, M. 2011. Development of rapid in-field loop-mediated isothermal amplification (LAMP) assays for phytoplasmas. Bull. Insectol. 64:S41-S42.

ISTA. 2018. Seed Health Methods 2018. International Seed Testing Association, Bassersdorf, Switzerland. https://www.seedtest.org/en/seed-health-methodscontent---1--1452.html

Ito, S., and Kimura, J. 1931. Studies on the Bakanae disease of the rice plant. Rep. Hokkaido Agric. Exp. Stn. 27:1-95. 
Jeong, H., Lee, S., Choi, J., Lee, T., and Yun, S. 2013. Draft genome sequence of Fusarium fujikuroi B14, the causal agent of the bakanae disease of rice. Genome Announc. 1:e00035-13.

Kaneko, H., Kawana, T., Fukushima, E., and Suzutani, T. 2007. Tolerance of loopmediated isothermal amplification to a culture medium and biological substances. J. Biochem. Biophys. Methods 70:499-501.

Kumar, A., Sheoran, N., Prakash, G., Ghosh, A., Chikara, S. K., Rajashekara, H., Singh, U. D., Aggarwal, R., and Jain, R. K. 2017. Genome sequence of a unique Magnaporthe oryzae RMg-Dl isolate from India that causes blast disease in diverse cereal crops, obtained using PacBio single-molecule and Illumina HiSeq2500 sequencing. Genome Announc. 5:e01570-16.

Manandhar, H. K., Lyngs Jørgensen, H. J., Mathur, S. B., and Smedegaard-Petersen, V. 1998. Suppression of rice blast by preinoculation with avirulent Pyricularia oryzae and the nonrice pathogen Bipolaris sorokiniana. Phytopathology 88: 735-739.

Mathur, S. B., and Kongsdal, O. 2003. Common laboratory seed health testing methods for detecting fungi. Online publication. International Seed Testing Association, Bassersdorf, Switzerland. https://catalog.hathitrust.org/Record/ 009176889

Matic, S., Gullino, M. L., and Spadaro, D. 2017. The puzzle of bakanae disease through interactions between Fusarium fujikuroi and rice. Front. Biosci. Elite 9:333-344.

Mori, Y., Kitao, M., Tomita, N., and Notomi, T. 2004. Real-time turbidimetry of LAMP reaction for quantifying template DNA. J. Biochem. Biophys. Methods 59:145-157.

Nagamine, K., Watanabe, K., Ohtsuka, K., Hase, T., and Notomi, T. 2001. Loopmediated isothermal amplification reaction using a nondenatured template. Clin. Chem. 47:1742-1743.

Notomi, T., Okayama, H., Masubuchi, H., Yonekawa, T., Watanabe, K., Amino, N., and Hase, T. 2000. Loop-mediated isothermal amplification of DNA. Nucleic Acids Res. 28:e63.

O'Donnell, K., and Cigelnik, E. 1997. Two divergent intragenomic rDNA ITS2 types within a monophyletic lineage of the fungus Fusarium are nonorthologous. Mol. Phylogenet. Evol. 7:103-116.

Oerke, E. C., and Dehne, H. W. 2004. Safeguarding production-Losses in major crops and the role of crop protection. Crop Prot. 23:275-285.

Ou, S. H. 1985. Rice Diseases. Commonwealth Agricultural Bureaux, Slough, United Kingdom.
Schrader, C., Schielke, A., Ellerbroek, L., and Johne, R. 2012. PCR inhibitorsOccurrence, properties and removal. J. Appl. Microbiol. 113:1014-1026.

Siciliano, I., Amaral Carneiro, G., Spadaro, D., Garibaldi, A., and Gullino, M. L. 2015. Jasmonic acid, abscisic acid and salicylic acid are involved in the phytoalexin responses of rice to Fusarium fujikuroi, a high gibberellin producer pathogen. J. Agric. Food Chem. 63:8134-8142.

Sun, S. K., and Snyder, W. C. 1981. The Bakanae disease of the rice plant. Pages 104-113 in: Fusarium: Diseases, Biology and Taxonomy. P. E. Nelson, T. A. Toussoun, and R. J. Cook, eds. The Pennsylvania State University, University Park

Su'udi, M., Kim, J., Park, J.-M., Bae, S.-C., Kim, D., Kim, Y.-H., and Ahn, I. P. 2013. Quantification of rice blast disease progressions through TaqMan realtime PCR. Mol. Biotechnol. 55:43-48.

Teng, P. S. 1994. Integrated pest management in rice. Exp. Agric. 30:115-137.

Tian, S., Nakamura, K., and Kayahara, H. 2004. Analysis of phenolic compounds in white rice, brown rice, and germinated brown rice. J. Agric. Food Chem. 52:4808-4813.

Tomlinson, J. A., Boonham, N., and Dickinson, M. 2010a. Development and evaluation of a one-hour DNA extraction and loop-mediated isotherma amplification assay for rapid detection of phytoplasmas. Plant Pathol. 59: 465-471.

Tomlinson, J. A., Dickinson, M. J., and Boonham, N. 2010b. Rapid detection of Phytophthora ramorum and $P$. kernoviae by two-minute DNA extraction followed by isothermal amplification and amplicon detection by generic lateral flow device. Phytopathology 100:143-149.

Tomlinson, J. A., Dickinson, M., Hobden, E., Robinson, S., Giltrap, P. M., and Boonham, N. 2010c. A five-minute DNA extraction method for expedited detection of Phytophthora ramorum following prescreening using Phytophthora spp. lateral flow devices. J. Microbiol. Methods 81:116-120.

Tomlinson, J. A. Ostoja-Starzewska, S., Adams, I. P., Miano, D. W., Abidrabo, P., Kinyua, Z., Alicai, T., Dickinson, M. J., Peters, D., Boonham, N., and Smith, J. 2013. Loop-mediated isothermal amplification for rapid detection of the causal agents of cassava brown streak disease. J. Virol. Methods 191: $148-154$

Villari, C., Mahaffee, W. F., Mitchell, T. K., Pedley, K. F., Pieck, M. L., and Peduto Hand, F. 2017. Early detection of airborne inoculum of Magnaporthe oryzae in turfgrass fields using a quantitative LAMP assay. Plant Dis. 101: 170-177. 